\title{
PD-L1 and C-MET expression and survival in patients with small cell lung cancer
}

\author{
Lulu Miao ${ }^{1, *}$, Yunyun Lu', ${ }^{1, *}$ Yanjun $X u^{1}$, Gu Zhang ${ }^{2}$, Zhiyu Huang ${ }^{1}$, Lei Gong ${ }^{1}$ and \\ Yun Fan ${ }^{1}$ \\ ${ }^{1}$ Department of Thoracic Medical Oncology, Hangzhou, 310022, Zhejiang, People's Republic of China \\ ${ }^{2}$ Department of Pathology, Zhejiang Cancer Hospital, Hangzhou, 310022, Zhejiang, People's Republic of China \\ *These authors have contributed equally to this work \\ Correspondence to: Yun Fan, email: fanyun@csco.org.cn \\ Keywords: small cell lung cancer, PD-LI, C-MET, expression, prognosis \\ Received: October 31,2015 Accepted: April 29, $2016 \quad$ Published: June 1, 2016 \\ Copyright: Miao et al. This is an open-access article distributed under the terms of the Creative Commons Attribution License 3.0 \\ (CC BY 3.0), which permits unrestricted use, distribution, and reproduction in any medium, provided the original author and source \\ are credited.
}

\section{ABSTRACT}

Background: Blocking the binding between the PD-1 and PD-L1 has been reported to produce antitumor responses. The MET/HGF axis appears to be another signaling pathway frequently altered in small cell lung cancer (SCLC). Our study was aimed to investigate the expression and prognostic roles of PD-L1 and C-MET in SCLC.

Methods: The expression levels of PD-L1 and C-MET were evaluated by immunohistochemical analysis in 83 SCLC specimens. Survival analysis was performed using the Kaplan-Meier method.

Results: Of the SCLC specimens, $51.8 \%$ and $25.3 \%$ exhibited positivity for PD-L1 and C-MET, respectively. Higher PD-L1 expression in tumor specimens was significantly correlated with a limited disease (LD) stage, normal levels of serum lactate dehydrogenase (LDH) and neuron-specific enolase (NSE). No association was found between the levels of C-MET and PD-L1 expression or between C-MET expression and other clinical characteristics. SCLC patients with PD-L1-positive tumors showed significantly longer overall survival (OS) than patients with PD-L1-negative tumors (17.0 vs 9.0, $\mathrm{p}=\mathbf{0 . 0 1 8}$ ). Conversely, those with positive c-MET expression exhibited a shorter OS trend $(12.0$ vs $15.0, p=0.186)$. However, sub-analysis of LD-stage patients revealed longer OS among the c-MET-negative group ( 25.0 vs $14.0 ; p=0.011)$. The OS of patients with positivity for both PD-L1 and C-MET showed no significant difference compared with other patients $(p=0.17)$. According to multivariate analyses, neither PD-L1 nor C-MET immunoreactivity was a prognostic factor.

Conclusion: Expression of PD-L1 was correlated with LD stage and might serve as a prognostic for better OS in SCLC patients. In LD-stage patients, high C-MET expression might be predictive of a poor outcome.

\section{INTRODUCTION}

Small cell lung cancer (SCLC), which accounts for approximately $13-15 \%$ of all primary lung cancers [1], is one of the most aggressive types of lung cancer. Patients with SCLC are staged as limited disease (LD) or extensive disease (ED) based on the anatomical extent. Approximately $60 \%-70 \%$ of SCLC patients are staged at the ED stage at the time of diagnosis [2]. Although SCLC is highly sensitive to initial chemo- and radiation therapy, most patients inevitably suffer from early relapse and acquired drug resistance. The prognosis of SCLC patients remains very poor. For LD patients, the median overall survival (mOS) is 16-24 months, with a two-year survival rate of $25 \%$. For ED patients, the mOS is $8-13$ months, with a dismal two-year survival rate of approximately 5\% [3]. Despite rapid progress in our knowledge of the molecular biology of non-small cell lung cancer (NCSLC) and the development of targeted therapy, 
conventional chemo- and radiation therapy for SCLC over the last few decades has remained largely unchanged [4]. Thus, to improve the outcome of SCLC patients, it is urgent to explore the underlying molecular mechanisms and immune-regulation in SCLC carcinogenesis.

As the aberrant activation of co-inhibitory pathways is a key determent of immune suppression, blocking immune checkpoints with monoclonal antibodies has recently emerged as a new therapeutic strategy in cancer treatment [5]. Programmed death 1 (PD-1), a receptor expressed on the surface of T cells, is involved in inhibitory signal transmission $[6,7]$. Its ligand, programmed deathligand 1 (PD-L1), is frequently overexpressed in many types of human cancer [8], inducing $\mathrm{T}$ cell impotence and ultimately achieving immune evasion. Recent clinical trials have shown the promising antitumor activity of PDL1 and PD-1 antibody blockade in various malignancies, including NSCLC and SCLC [9-13]. Albeit rare, there are also reports on the promising efficacy of PD-L1 and PD-1 antibodies in SCLC patients, both PD-L1-positive and PDL1-unselected populations [14-15]. Both PD-1 and PD-L1 are expressed on the surface of SCLC cells, though the biological implications and the exact functions of PD-1 and PD-L1 in SCLC remain unclear [16].

The MET/HGF axis appears to be another signaling pathway that when aberrant, is involved in SCLC invasiveness and progression [3]. Mesenchymal-epithelial transition (MET) factor receptor is activated upon binding its ligand hepatocyte growth factor (HGF), resulting in activation of different intracellular signaling pathways responsible for promoting proliferation and invasiveness. Furthermore, increasing evidence indicates that the activated MET pathway is a prognostic factor for a poor outcome in lung cancer and many other solid tumors [1720]. Regardless, there are limited data on the prevalence and prognostic role of MET expression in SCLC.

In the present study, we aimed to evaluate the expression levels of PD-L1 and MET as two potential therapeutic targets using IHC analysis of SCLC specimens and to further explore their clinical relevance and prognostic role in this aggressive malignancy.

\section{RESULTS}

\section{Patient characteristics}

The clinical characteristics of 83 SCLC patients were collected in our study (Table 1). The median age of the patients at diagnosis was 59 years (range $35-84$ years). The majority of patients were males ( 72 cases, 86.7\%). A total of 79 samples $(95.2 \%)$ were obtained from primary lung lesions and four (4.8\%) from metastatic sites, including lymph node metastasis in three (3.6\%) and brain metastasis in one $(1.2 \%)$. Among the specimens from lung tumors, 16 (19.3\%) were from lung cancer resections and 55 (66.3\%) from biopsy specimens by means of fiber bronchoscopy $(47,56.6 \%)$ or lung puncture $(8,9.6 \%)$. Thirty-six patients (43.4\%) had ED-stage and 47 (56.6\%) LD-stage disease at the time of diagnosis. Among the 47 LD-SCLC patients, $22(46.8 \%)$ received concurrent or sequential chemoradiotherapy, 15 (31.9\%) underwent surgical resection followed by chemotherapy, and $10(21.3 \%)$ received single chemotherapy or radiotherapy. The ED-SCLC patients were treated with first-line chemotherapy, and one of them also received palliative resection. The serum $\mathrm{LDH}$ level was higher than the normal limit of $240 \mathrm{IU} / \mathrm{L}$ in 12 patients $(14.5 \%)$, and 53 patients $(63.9 \%)$ had abnormally increased NSE serum levels (higher than $17.0 \mathrm{ng} / \mathrm{ml}$ ).

\section{PD-L1 and c-MET expression}

Immunoreactivity for PD-L1 was observed in the membrane and/or cytoplasm of tumor cells and stromal lymphocytes (Figure 1). The median PD-L1 expression score was 15 . Forty-three $(51.8 \%)$ patients exhibited positive tumor staining for PD-L1. Immunostaining for c-Met was found in the cytoplasm of tumor cells and was positive in 21 cases $(25.3 \%)$. The median c-MET expression score was 20 . Among all 83 SCLC patients, 14 (16.9\%) were found to express both PD-L1 and c-MET.

\section{Correlation between PD-L1 and patient characteristics}

A higher expression level of PD-L1 in tumor specimens was significantly correlated with a limited disease (LD) stage ( $\mathrm{p}=0.004)$, a normal serum LDH level $(\mathrm{p}=0.031)$, and a normal NSE level $(\mathrm{p}=0.005)$ (Figure 2$)$. No association was found between the levels of PD-L1 and c-MET expression $(\mathrm{p}=0.082)$.

\section{Correlation between c-MET and patient characteristics}

No significant correlation was observed between c-MET expression and disease stage (LD vs ED, $\mathrm{p}=0.450$ ), serum LDH level (normal vs abnormal, $\mathrm{p}=0.972$ ), serum NSE level (normal vs abnormal, $p=0.824$ ), age $(<70$ vs $\geq 70$, $\mathrm{p}=0.235$ ), sex (male vs female, $\mathrm{p}=0.262$ ) or other clinical characteristics. The relationship between PD-L1 or c-MET expression and patient demographics is shown in Table 1.

\section{Survival analysis}

We analyzed the outcomes of patients according to the immunohistochemical status of PD-L1 and c-MET. SCLC patients with PD-L1-positive tumors showed significantly longer overall survival (OS) than patients with PD-L1-negative tumors (median OS, 17.0 vs 9.0, $\mathrm{p}=0.018$ ) (Figure 3). Sub-analysis of the LD-SCLC patients showed no significant difference in OS between the PD-L1-positive and -negative groups (22.0 vs 16.0, $\mathrm{p}=0.10$ ) (Figure 4). Similarly, no significant difference in OS was found for the ED-SCLC patients (8.0 vs 6.0, 
Table 1: Association between PD-L1 or c-MET expression and clinicopathological characteristics of SCLC patients

\begin{tabular}{|c|c|c|c|c|c|c|c|}
\hline \multirow{2}{*}{ Variables } & \multirow{2}{*}{$\begin{array}{c}\text { No. of } \\
\text { patients }\end{array}$} & \multicolumn{2}{|c|}{ PD-L1 expression } & \multirow{2}{*}{ p-value } & \multicolumn{2}{|c|}{ c-MET expression } & \multirow{2}{*}{ p-valuc } \\
\hline & & Positive & Negative & & Positive & Negative & \\
\hline \multicolumn{8}{|l|}{ Age } \\
\hline$<70$ & 75 & 40 & 35 & 0.902 & 20 & 55 & 0.235 \\
\hline$\geq 70$ & 8 & 3 & 5 & & 1 & 7 & \\
\hline \multicolumn{8}{|l|}{ Sex } \\
\hline Male & 72 & 37 & 35 & 0.953 & 18 & 54 & 0.262 \\
\hline Female & 11 & 6 & 6 & & 3 & 8 & \\
\hline \multicolumn{8}{|l|}{ PS status } \\
\hline $0-1$ & 80 & 42 & 38 & 0.229 & 20 & 60 & 0.763 \\
\hline $2-3$ & 3 & 1 & 2 & & 1 & 2 & \\
\hline \multicolumn{8}{|l|}{ Stage } \\
\hline LD & 47 & 29 & 18 & 0.004 & 10 & 37 & 0.450 \\
\hline ED & 36 & 14 & 22 & & 11 & 25 & \\
\hline \multicolumn{8}{|l|}{ LDH } \\
\hline Normal & 71 & 40 & 31 & 0.031 & 17 & 54 & 0.972 \\
\hline Abnormal & 12 & 3 & 9 & & 4 & 8 & \\
\hline \multicolumn{8}{|l|}{ NSE } \\
\hline Normal & 30 & 21 & 9 & 0.005 & 6 & 24 & 0.824 \\
\hline Abnormal & 53 & 22 & 32 & & 15 & 38 & \\
\hline
\end{tabular}

$\mathrm{p}=0.29$ ) (Figure 5). Those SCLC patients with positive c-MET expression exhibited a trend of shorter OS $(12.0$ vs $15.0, \mathrm{p}=0.186)$, but the difference was not significant (Figure 6). However, sub-analysis of the LD-stage patients revealed a longer OS for the c-MET-negative group (25.0 vs $14.0 ; p=0.011$ ) (Figure 7 ). The OS of patients showing positivity for both PD-L1 and c-MET was not significantly different from that of the other patients $(p=0.17)$. Multivariate analyses revealed that LD stage and good performance status, but not PD-L1 or c-MET immunoreactivity, were independently predictive of better OS (Table 2).

\section{DISCUSSION}

Antibody-induced blockade of PD-L1 has resulted in durable tumor regression and prolonged disease stabilization in patients with advanced cancers, including NSCLC, melanoma, and renal-cell cancer [11]. Indeed, the success of blocking co-inhibitory pathways in many malignant neoplasms has inspired more confidence and enthusiasm in antitumor therapy. However, clinical research on the relationship between PD-L1 and SCLC is rare. Several studies have shown that PD-L1 expression may serve as a prognostic factor. PD-L1 expression by tumors has also been theorized to be a potential biomarker for patients who may have higher response rates to PD-1 pathway-targeting agents. However, the results to date are contradictory. MET, another crucial process that represents one of the most important mechanisms of progression and invasiveness [21-22], is also a potential therapeutic target. In contrast to the strong evidence for the involvement of MET in NSCLC, limited data are available for SCLC and MET. Given the insufficient treatment options in SCLC and its poor prognosis, we decided to examine the expression of PD-L1 and c-MET and their clinical correlation in SCLC.

Our data showed that high levels of PL-L1 expression were correlated with LD stage and normal levels of LDH and NSE. These results were consistent with Hidenobu's study including 102 SCLC patients [23]. Survival analysis also showed that SCLC patients with PD-L1-positive tumors had significantly longer OS. However, our multivariate analyses revealed that PD-L1 immunoreactivity was not predictive of better OS. Previous results on the prognostic role of PD-L1 expression are also controversial. Some reports have shown PD-L1 protein expression to be associated with better prognosis in patients with lung cancer, colorectal 

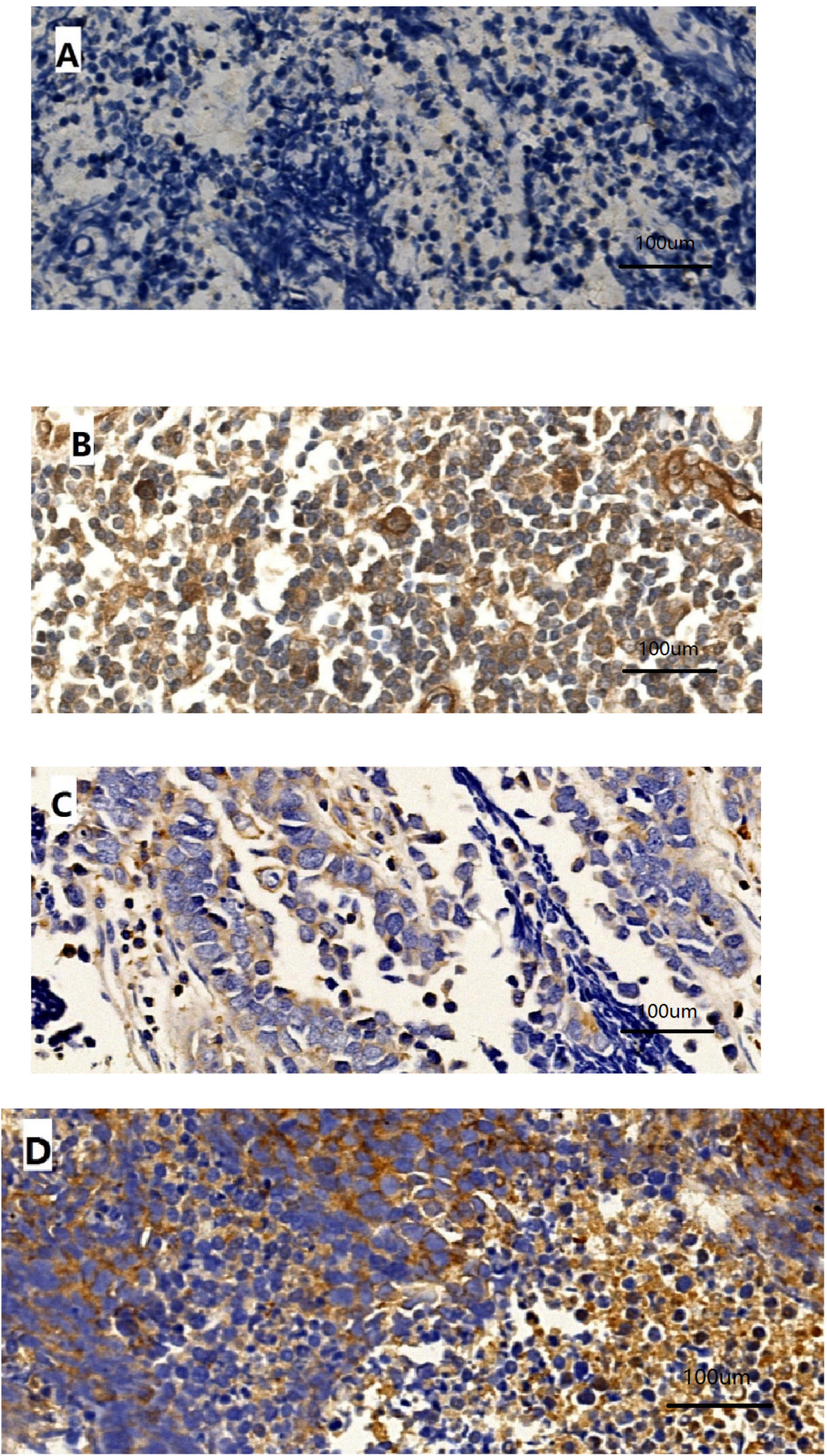

Figure 1: Representative patterns of PD-L1 immunostaining in SCLC tumors with negative A. or strong positive B. staining intensity and c-MET immunostaining with negative $\mathbf{C}$. or strong positive D. staining intensity. Original magnification, $\times 400$. 
cancer, breast cancer, and malignant melanoma [2329]. In contrast, other studies have reported that PD-L1 expression is associated with poor prognosis in patients with NSCLC, gastric carcinoma, hepatocellular carcinoma and pancreatic cancer [30-33]. There are several possible explanations for the conflicting results. First, the human immune system is a dynamic, precisely regulated, multistep process, and PD-L1 is an inducible marker that can be upregulated or downregulated over time [34]. Second, determination of PD-1 expression is generally performed via immunohistochemistry, using various antibodies in different malignancies. Third, the threshold for PD-L1 positivity differed among previous studies. In our study, we defined positive PD-L1 expression as staining in more than $5 \%$ of tumor cells, the same criteria used in clinical trials [12]. The optimal threshold for PD-L1 positivity in terms of prognosis discrimination remains undefined and deserves further investigation in future clinical trials.

The results of our study showed that expression of c-MET was relatively less common, in only $25.3 \%$ of SCLC specimens, and no statistically significant
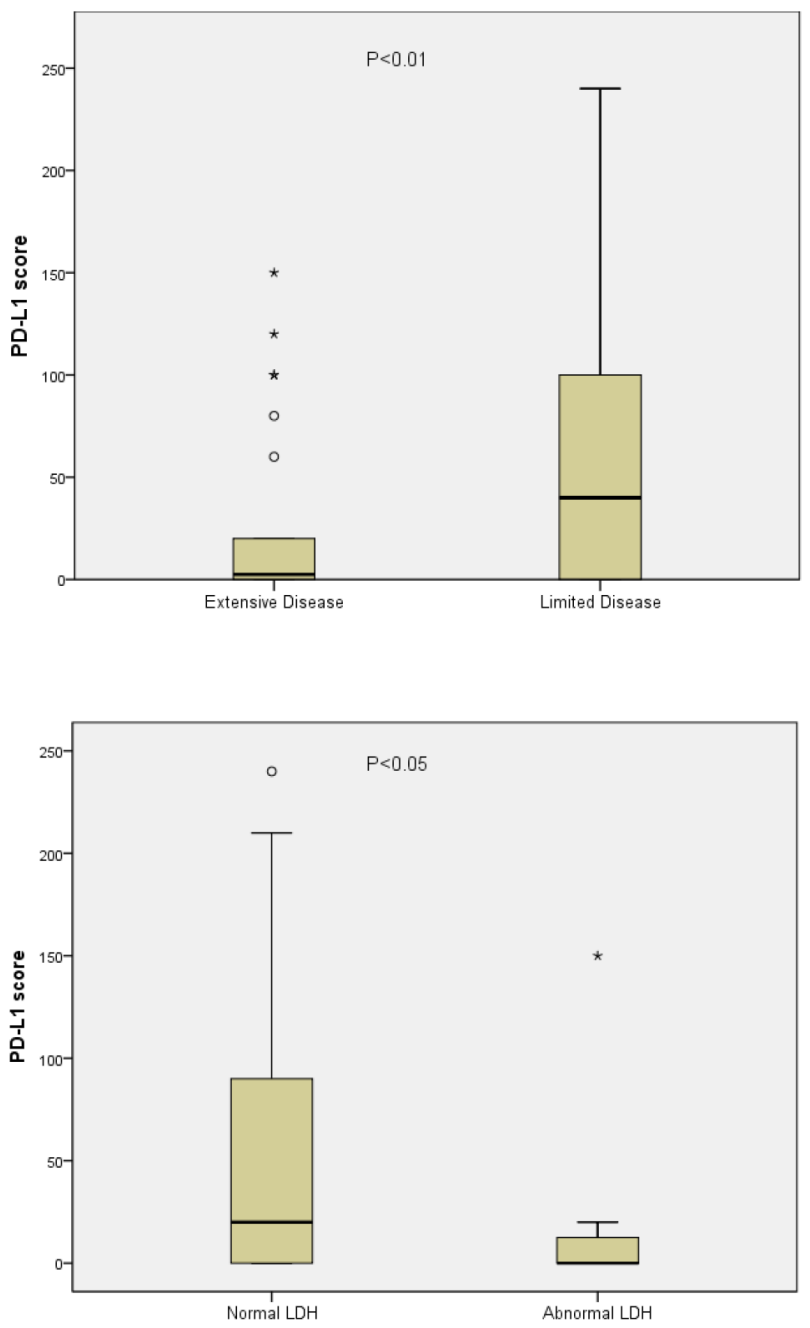

correlations were observed between c-MET expression and disease stage or other clinical characteristics or survival outcome. However, sub-analysis of LD-stage patients showed a longer OS for the c-MET-negative group. Although several clinical studies in patients with NSCLC have demonstrated that MET overexpression is associated with a poor survival rate [35-38], in our study, the prognostic significance of MET overexpression was only found in SCLC LD-stage patients. The accuracy of the results may be influenced by the immunohistochemical methodology employed. Further research is needed to clarify the prognostic role of the MET signaling pathway using different methods, such as fluorescence in situ hybridization (FISH) and gene sequencing.

Previous studies have shown that PD-L1 expression is driven by various oncogenic signaling pathways. For example, Azuma found that high PD-L1 expression is associated with the presence of EGFR mutations in surgically resected NSCLC [39]. Tang Y also reported that PD-L1 tended to be associated with mutant EGFR $(\mathrm{p}=0.067)[40]$. However, we did not find an association

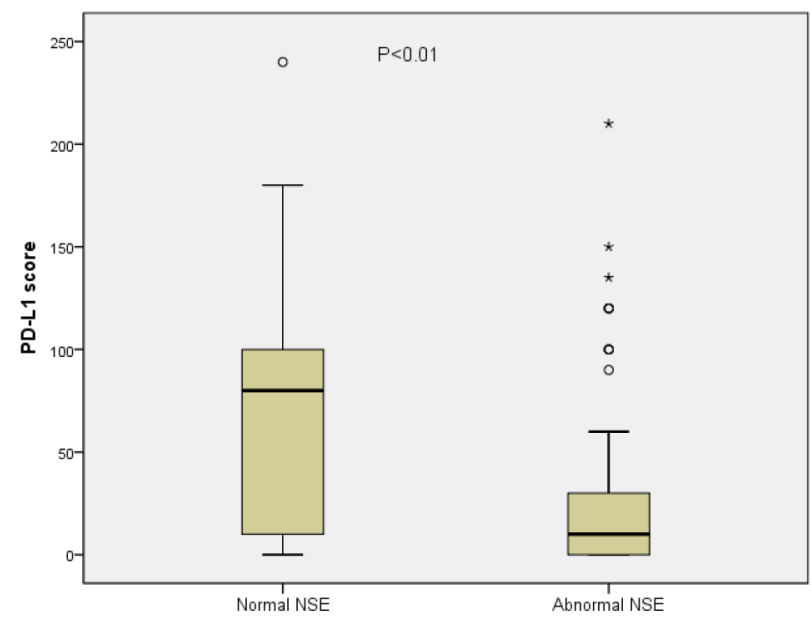

Figure 2: Significant association of PD-L1 staining score with disease stage, LDH level or NSE level. Data are presented as box-and-whisker plots, and p values were determined using the Wilcoxon rank-sum test. 


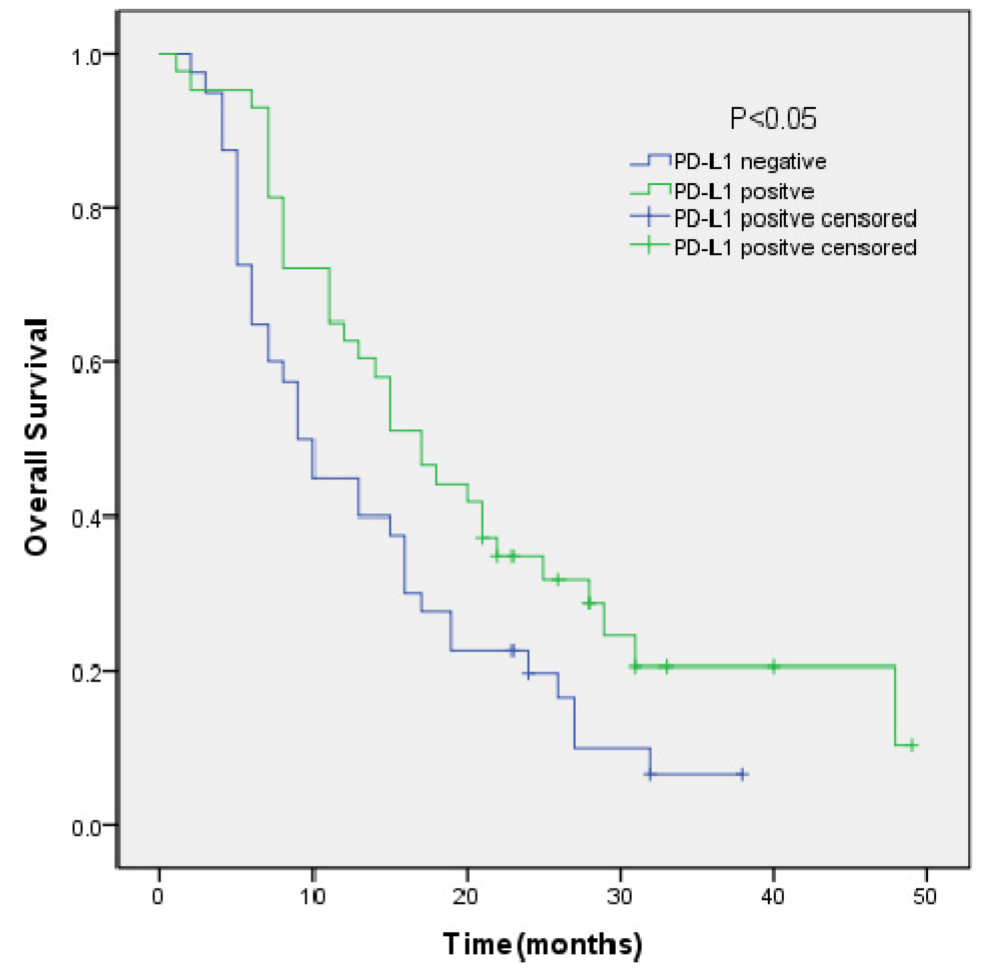

Figure 3: Kaplan-Meier curves of overall survival (OS) in PD-L1-positive vs PD-L1-negative patients. Overall survival of 83 SCLC patients in relation to PD-L1 status.

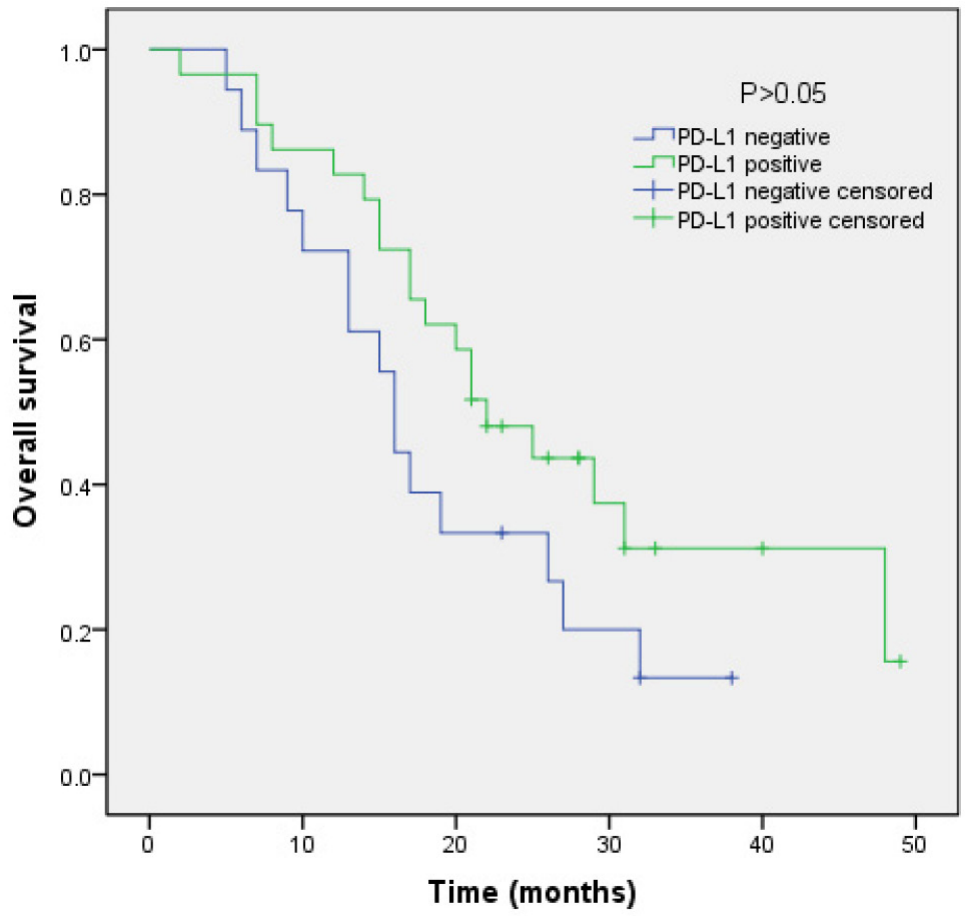

Figure 4: Kaplan-Meier curves of overall survival (OS) in PD-L1-positive vs PD-L1-negative patients with LD-stage disease. Overall survival of 47 SCLC patients with LD-stage disease in relation to PD-L1 status. 


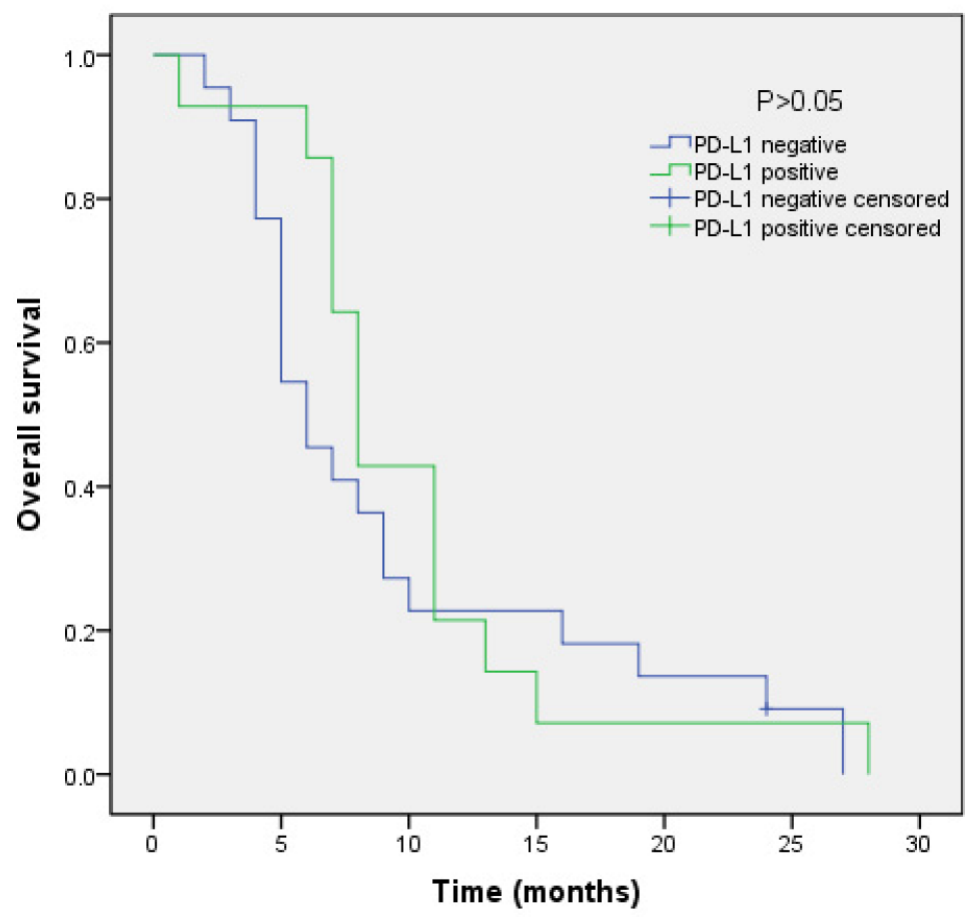

Figure 5: Kaplan-Meier curves of overall survival (OS) in PD-L1-positive vs PD-L1-negative patients with ED-stage disease. Overall survival of 36 SCLC patients with ED-stage disease in relation to PD-L1 status.

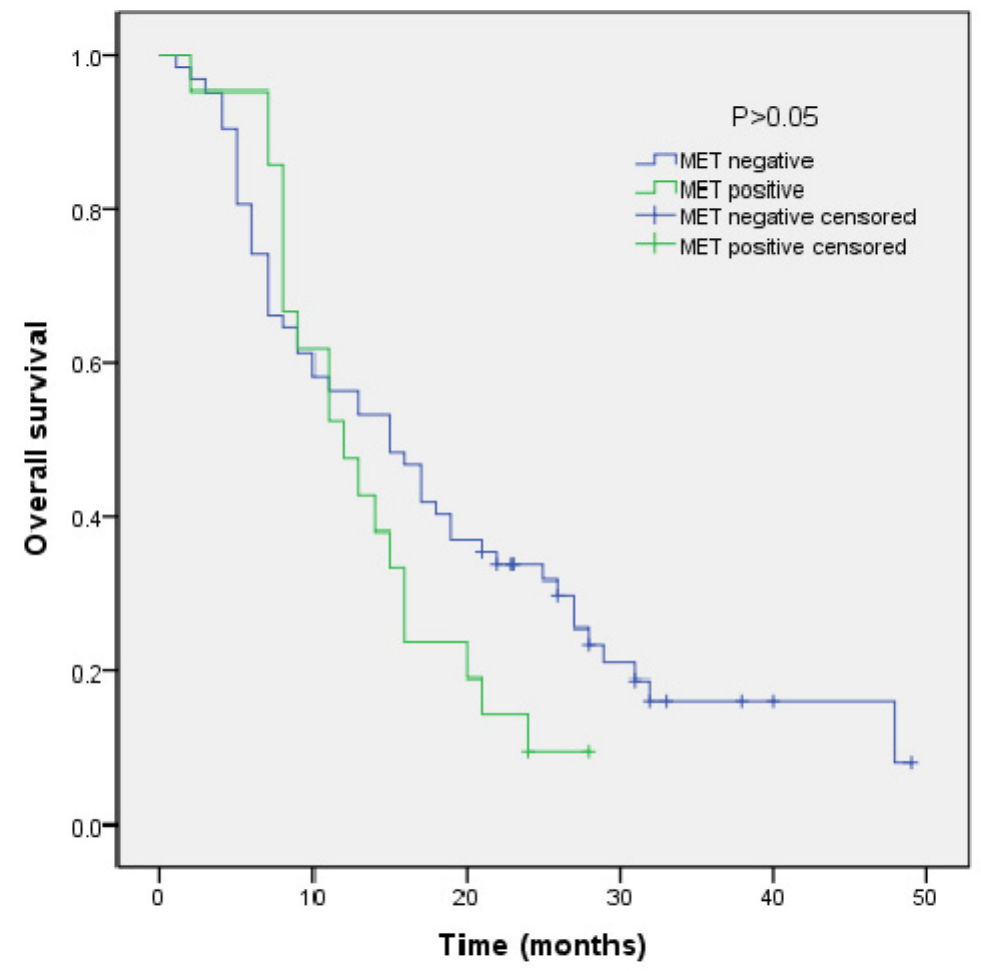

Figure 6: Kaplan-Meier curves of overall survival (OS) in MET-positive vs -negative patients. Overall survival of 83 SCLC patients in relation to c-MET status. 
Table 2: Multivariate analysis factors for overall survival

\begin{tabular}{lccc}
\hline Factor & Hazard ratio & $\mathbf{9 5 \%}$ CI & p-value \\
\hline PS (0-1/2-3) & 2.808 & $1.111-7.098$ & 0.029 \\
Stage (LD/ED) & 3.364 & $1.901-5.953$ & $<0.001$ \\
NSE level (Low/High) & 1.673 & $0.925-3.027$ & 0.089 \\
LDH level (Normal/ & 1.220 & $0.580-2.568$ & 0.600 \\
Abnormal) & & & 0.820 \\
PD-L1 expression (Positive/ & 0.943 & & 0.307 \\
Negative) & & $0.401-1.333$ & \\
c-MET expression (Positive/ & 0.732 & & \\
Negative) & & & \\
\hline
\end{tabular}

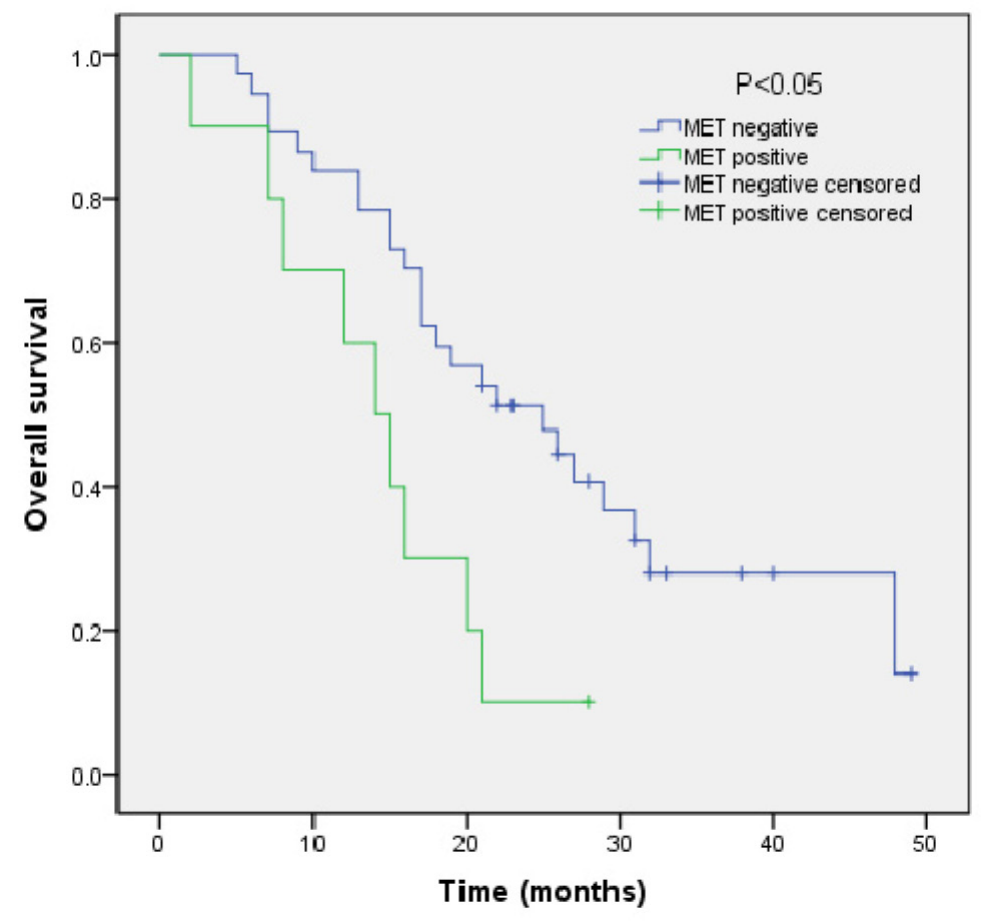

Figure 7: Kaplan-Meier curves of overall survival (OS) in MET-positive vs -negative patients with LD-stage disease. Overall survival of 47 SCLC patients with LD-stage disease in relation to c-MET status.

between PD-L1 expression and c-MET expression in our study. Further research is needed to elucidate the relation between PD-L1 expression and the MET signaling pathway.

Our study also had certain other limitations. First, the number of patients enrolled was relatively small. Second, as $47(56.6 \%)$ of the patients were LD-stage patients, the representativeness of the sample may not be adequate. Third, the therapies received by these patients were not standardized and might have affected survival outcomes. We expect that future large-sample studies, which could balance all relevant clinical factors, may further verify our findings.

In conclusion, we evaluated the expression of PDL1 and c-MET in patients with SCLC and found that PDL1 expression might be prognostic for a better OS. High expression levels of c-MET revealed a trend of worse outcomes associated with poor prognosis in LD-stage patients. Our results revealed the clinical relevance and potential prognostic roles of these two factors, providing a foundation for further research on immunotherapy or targeted therapy for SCLC. 


\section{PATIENTS AND METHODS}

\section{Patients}

We screened 158 patients diagnosed with SCLC at Zhejiang Cancer Hospital between July 2010 and December 2012. For immunohistochemistry analysis, we excluded 75 patients diagnosed using cytological specimens or whose tissue blocks contained too few tumor cells to allow the assay. Eighty-three of these patients who had adequate paraffin-embedded tumor specimens for immunohistochemical detection and with complete clinical and follow-up data were enrolled. This study was conducted in accordance with the provisions of the Declaration of Helsinki and was approved by the Institutional Review Board of Zhejiang Cancer Hospital.

\section{Immunohistochemical analysis}

Paraffin-embedded tumor tissue was sectioned at a thickness of $4 \mu \mathrm{m}$, and the sections were mounted on glass slides for immunohistochemical analysis of PD-L1 and c-MET with the use of the BenchMark XT platform (Ventana Automated Systems, Tucson, AZ). Standard indirect immunoperoxidase procedures were used for IHC. Briefly, slides were dewaxed and rehydrated in distilled water. Endogenous peroxidase activity was blocked using $0.5 \% \mathrm{H}_{2} \mathrm{O}_{2}$. The sections were treated with 10\% normal goat serum (DakoCytomation; Dako, Carpinteria, CA, USA) for 20 minutes and incubated with primary antibodies against PD-L1 (anti-B7-H1/ PD-L1/CD274 Antibody, clone SP66, SPRINGBIO, USA) and c-MET (ZA-0547, clone SP142, SPRINGBIO, USA) at room temperature. The sections were further incubated with a peroxidase-labeled secondary antibody (Polymer HRP Goat anti-Mouse \& Rabbit IgG (Cat No. D22-110)) for 30 minutes at room temperature. For visualization of the antigen, the sections were immersed in 3-amino-9-ethylcarbazole plus substrate-chromogen (DakoCytomation) for 30 minutes and counterstained with Gill's hematoxylin.

Two well-experienced pathologists examined the immunohistochemical slides without any prior information on the clinicopathological features of the patient samples. The percentages of PD-L1- and c-METpositive tumor cells and staining intensity were evaluated for each sample. The intensity of staining was evaluated according to the following scale: 0 , no staining; 1 , weak staining; 2, moderate staining; and 3, strong staining. A semi-quantitative approach was used to generate a score for each tissue core. The percentage of stained cells $(0$ $100 \%$ ) was multiplied by the dominant intensity pattern of staining, ranging from 0 to 3 . Therefore, the overall semiquantitative score ranged from 0 to 300 . In the absence of any standardized scoring system, tumors with PD-L1 staining in over $5 \%$ of the cells were scored as positive for PD-L1 expression, according to previous studies $[8,41-$
42]. Tumors with strong c-MET staining in at least $10 \%$ or weak to moderate staining in at least $40 \%$ of the cells were scored as positive for c-MET expression [43].

\section{Statistical analysis}

Statistical analyses were performed using the SPSS analytical software (IBM). Clinical characteristics and their correlations with PD-L1 or c-MET expression were examined using the $\chi^{2}$ test or Fisher's exact test. Differences between the PD-L1 or c-MET median score were analyzed using the Wilcoxon rank-sum test. Overall survival (OS) was measured from the administration of treatment until the date of death or last follow-up. Survival curves were generated using the Kaplan-Meier method, and the log-rank test was used to assess the statistical significance of the differences between two groups. Further multivariate survival analysis was conducted using the Cox regression model. Statistical significance was defined as $\mathrm{p}<0.05$.

\section{ACKNOWLEDGMENTS}

This study was supported by the National Natural Science Funds of China (Grant No. 81372263).

\section{CONFLICTS OF INTEREST}

The authors declare that have no conflicts of interest.

\section{REFERENCES}

1. Travis WD. Update on small cell carcinoma and its differentiation from squamous cell carcinoma and other non-small cell carcinomas. ModPathol. 2012; 25:S18-30.

2. Lally BE, Urbanic JJ, Blackstock AW, Miller AA, Perry MC. Small cell lung cancer: have we made any progress over the last 25 years? Oncologist. 2007; 12:1096-1104.

3. Gelsomino F, Rossi G, Tiseo M. MET and Small-Cell Lung Cancer. Cancers. 2014; 6:2100-2115.

4. Metro G, Duranti S, Fischer MJ, Cappuzzo F, Crinò L. Emerging drugs for small cell lung cancer-an update. Expert OpinEmerg Drugs. 2012; 17:31-36.

5. Pardoll DM. The blockade of immune checkpoints in cancer immunotherapy. Nat Rev Cancer. 2012; 12:252-264.

6. Zhang X, Schwartz JC, Guo X, Bhatia S, Cao E, Lorenz M, Cammer M, Chen L, Zhang ZY, Edidin MA, Nathenson SG, Almo SC. Structural and functional analysis of the costimulatory receptor programmed death-1. Immunity. 2004; 20:337-347.

7. Riley JL. PD-1 signaling in primary $\mathrm{T}$ cells. Immunol Rev. 2009; 229:114-125.

8. Parsa AT, Waldron JS, Panner A, Crane CA, Parney IF, Barry JJ, Cachola KE, Murray JC, Tihan T, Jensen MC, Mischel PS, Stokoe D, Pieper RO. Loss of tumor 
suppressor PTEN function increase B7-H1 expression and immunoresistance in glioma. Nat Med. 2007; 13:84-88.

9. Topalian SL, Sznol M, McDermott DF, Kluger HM, Carvajal RD, Sharfman WH, Brahmer JR, Lawrence DP, Atkins MB, Powderly JD, Leming PD, Lipson EJ, Puzanov I, et al. Survival, durable tumor remission, and long-term safety in patients with advanced melanoma receiving nivolumab. J Clin Oncol. 2014; 32:1020-1030.

10. Brahmer JR, Drake CG, Wollner I, Powderly JD, Picus J, Sharfman WH, Stankevich E, Pons A, Salay TM, McMiller TL, Gilson MM, Wang C, Selby M, et al. Phase I study of singleagent anti-programmed death-1 (MDX1106) in refractory solid tumors: safety, clinical activity, pharmacodynamics, and immunologic correlates. J Clin Oncol. 2010; 28:3167-3175.

11. Brahmer JR, Tykodi SS, Chow LQ, Hwu WJ, Topalian SL, Hwu P, Drake CG, Camacho LH, Kauh J, Odunsi K, Pitot HC, Hamid O, Bhatia S, et al. Safety and activity of antiPD-L1 antibody in patients with advanced cancer. N Engl J Med. 2012; 366:2455-2465.

12. Topalian SL, Hodi FS, Brahmer JR, Gettinger SN, Smith DC, McDermott DF, Powderly JD, Carvajal RD, Sosman JA, Atkins MB, Leming PD, Spigel DR, Antonia SJ, et al. Safety, activity, and immune correlates of anti-PD-1 antibody in cancer. N Engl J Med. 2012; 366:2443-2454.

13. Taube JM, Klein AP, Brahmer JR, Xu H, Pan X, Kim JH, Chen L, Pardoll DM, Topalian SL, Anders RA. Association of PD-1, PD-1 ligands, and other features of the tumor immune microenvironment with response to anti-PD-1 therapy. Clin Cancer Res. 2014; 20:5064-5074.

14. Ott PA, Fernandez MEE, Hiret S, Kim DW, Moss RA, Winser T, Yuan S, Cheng JD, Piperdi B, Mehnert J. Pembrolizumab (MK-3475) in patients (pts) with extensivestage small cell lung cancer (SCLC): Preliminary safety and efficacy results from KEYNOTE-028. J Clin Oncol. 2015.

15. Taylor M, Antonia S, Bendell J, Calvo E, Jäger D, de Braud F, Ott PA, Pietanza MC, Horn L, Le DT, Morse MA, LópezMartin JA, Ascierto PA, et al. Phase I/II study of nivolumab with or without ipilimumab for treatment of recurrent small cell lung cancer (SCLC): CA209-032. J Clin Oncol. 2015.

16. Yamane H, Isozaki H, Takeyama M, Ochi N, Kudo K, Honda Y, Yamagishi T, Kubo T, Kiura K, Takigawa N. Programmed cell death protein 1 and programmed deathligand 1 are expressed on the surface of some small-cell lung cancer lines. Am J Cancer Res. 2015; 5:1553-1557.

17. Arriola E, Cañadas I, Arumí-Uría M, Dómine M, LopezVilariño JA, Arpí O, Salido M, Menéndez S, Grande E, Hirsch FR, Serrano S, Bellosillo B, Rojo F, et al. MET phosphorylation predicts poor outcome in small cell lung carcinoma and its inhibition blocks HGF-induced effects in MET mutant cell lines. Br J Cancer. 2011; 105:814-823.

18. Park S, Choi YL, Sung CO, An J, Seo J, Ahn MJ, Ahn JS, Park K, Shin YK, Erkin OC, Song K, Kim J, Shim YM,
Han J. High MET copy number and MET overexpression: Poor outcome in non-small cell lung cancer patients. Histol Histopathol. 2012; 27:197-207.

19. Shattuck DL, Miller JK, Carraway KL 3rd, Sweeney C. Met receptor contributes to trastuzumab resistance of Her2overexpressing breast cancer cells. Cancer Res. 2008; 68:1471-1477.

20. Sawada K, Radjabi AR, Shinomiya N, Kistner E, Kenny H, Becker AR, Turkyilmaz MA, Salgia R, Yamada SD, Vande Woude GF, Tretiakova MS, Lengyel E. c-Met overexpression is a prognostic factor in ovarian cancer and an effective target for inhibition of peritoneal dissemination and invasion. Cancer Res. 2007; 67:1670-1679.

21. Danilkovitch-Miagkova A, Zbar B. Dysregulation of Met receptor tyrosine kinase activity in invasive tumors. J Clin Invest. 2002; 109:863-867.

22. Boccaccio C, Comoglio PM. Invasive growth: A METdriven genetic programme for cancer and stem cells. Nat Rev Cancer. 2006; 6:637-645.

23. Ishii H, Azuma K, Kawahara A, Yamada K, Imamura Y, Tokito T, Kinoshita T, Kage M, Hoshino T. Significance of programmed cell death-ligand 1 expression and its association with survival in patients with small cell lung cancer. J Thorac Oncol. 2015; 10:426-430.

24. Yang CY, Lin MW, Chang YL, Wu CT, Yang PC. Programmed cell death-ligand 1 expression in surgically resected stage I pulmonary adenocarcinoma and its correlation with driver mutations and clinical outcomes. Eur J Cancer. 2014; 50:1361-1369.

25. Velcheti V, Schalper KA, Carvajal DE, Anagnostou VK, Syrigos KN, Sznol M, Herbst RS, Gettinger SN, Chen L, Rimm DL. Programmed death ligand-1 expression in nonsmall lung cancer. Lab Invest. 2014; 94:107-116.

26. Droeser RA, Hirt C, Viehl CT, Frey DM, Nebiker C, Huber X, Zlobec I, Eppenberger-Castori S, Tzankov A, Rosso R, Zuber M, Muraro MG, Amicarella F, et al. Clinical impact of programmed cell death ligand 1 expression in colorectal cancer. Eur J Cancer. 2013; 49:2233-2242.

27. Schalper KA, Velcheti V, Carvajal D, Wimberly H, Brown J, Pusztai L, Rimm DL. In situ tumor PD-L1 mRNA expression is associated with increased TILs and better outcome in breast carcinomas. Clin Cancer Res. 2014; 20:2773-2782.

28. Hino R, Kabashima K, Kato Y, Yagi H, Nakamura M, Honjo T, Okazaki T, Tokura Y. Tumor cell expression of programmed cell death-1 ligand 1 is a prognostic factor for malignant melanoma. Cancer. 2010; 116:1757-1766.

29. Lipson EJ, Vincent JG, Loyo M, Kagohara LT, Luber BS, Wang H, Xu H, Nayar SK, Wang TS, Sidransky D, Anders RA, Topalian SL, Taube JM. PD-L1 expression in Merkel cell carcinoma microenvironment: association with inflammation, Merkel cell polyomavirus, and overall survival. Cancer Immunol Res. 2013; 1:54-63. 
30. Chen YB, Mu CY, Huang JA. Clinical significance of programmed death-1 ligand-1 expression in patients with non-small cell lung cancer: a 5-year-follow-up study. Tumori. 2012; 98:751-755.

31. Wu C, Zhu Y, Jiang J, Zhao J, Zhang XG, Xu N. Immunohistochemical localization of programmed death-1 ligand-1 (PD-L1) in gastric carcinoma and its clinical significance. ActaHistochem. 2006; 108:19-24.

32. Gao Q, Wang XY, Qiu SJ, Yamato I, Sho M, Nakajima Y, Zhou J, Li BZ, Shi YH, Xiao YS, Xu Y, Fan J. Overexpression of PD-L1 significantly associates with tumor aggressiveness and postoperative recurrence in human hepatocellular carcinoma. Clin Cancer Res. 2009; 15:971-979.

33. Nomi T, Sho M, Akahori T, Hamada K, Kubo A, Kanehiro H, Nakamura S, Enomoto K, Yagita H, Azuma M, Nakajima Y. Clinical significance and therapeutic potential of the programmed death-1 ligand/programmed death-1 pathway in human pancreatic cancer. Clin Cancer Res. 2007; 13:2151-2157.

34. Langer CJ. Emerging immunotherapies in the treatment of non-small cell lung cancer (NSCLC): the role of immune checkpoint inhibitors. Am J Clin Oncol. 2015; 38:422-430.

35. Nakamura Y, Niki T, Goto A, Morikawa T, Miyazawa K, Nakajima J, Fukayama M. c-Met activation in lung adenocarcinoma tissues: an immunohistochemical analysis. Cancer Sci. 2007; 98:1006-1013.

36. Ichimura E, Maeshima A, Nakajima $T$, Nakamura $T$. Expression of c-met/HGF receptor in human non-small cell lung carcinomas in vitro and in vivo and its prognostic significance. Jpn J Cancer Res. 1996; 87:1063-1069.

37. Takanami I, Tanaka F, Hashizume T, Kikuchi K, Yamamoto Y, Yamamoto T, Kodaira S. Hepatocyte growth factor and c-Met/hepatocyte growth factor receptor in pulmonary adenocarcinomas: an evaluation of their expression as prognostic markers. Oncology. 1996; 53:392-397.

38. Siegfried JM, Weissfeld LA, Singh-Kaw P, Weyant RJ, Testa JR, Landreneau RJ. Association of immunoreactive hepatocyte growth factor with poor survival in resectable non-small cell lung cancer. Cancer Res. 1997; 57:433-439.

39. Azuma K, Ota K, Kawahara A, Hattori S, Iwama E, Harada T, Matsumoto K, Takayama K, Takamori S, Kage M, Hoshino T, Nakanishi Y, Okamoto I. Association of PD-L1 overexpression with activating EGFR mutations in surgically resected nonsmall-cell lung cancer. Ann Oncol. 2014; 25:1935-1940.

40. Tang Y, Fang W, Zhang Y, Hong S, Kang S, Yan Y, Chen N, Zhan J, He X, Qin T, Li G, Tang W, Peng P, Zhang L. The association between PD-L1 and EGFR status and the prognostic value of PD-L1 in advanced non-small cell lung cancer patients treated with EGFR-TKIs. Oncotarget. 2015; 6:14209-14219. doi: 10.18632/oncotarget.3694.

41. Taube JM, Anders RA, Young GD, Xu H, Sharma R, McMiller TL, Chen S, Klein AP, Pardoll DM, Topalian SL, Chen L. Colocalization of inflammatory response with B7-h1 expression in human melanocytic lesions supports an adaptive resistance mechanism of immune escape. Sci Transl Med. 2012; 4:127ra37.

42. D'Incecco A, Andreozzi M, Ludovini V, Rossi E, Capodanno A, Landi L, Tibaldi C, Minuti G, Salvini J, Coppi E, Chella A, Fontanini G, Filice ME, et al. PD-1 and PD-L1 expression in molecularly selected non-small-cell lung cancer patients. Br J Cancer. 2015; 112:95-102.

43. Tachibana K, Minami Y, Shiba-Ishii A, Kano J, Nakazato Y, Sato Y, Goya T, Noguchi M. Abnormality of the hepatocyte growth factor/MET pathway in pulmonary adenocarcinogenesis. Lung Cancer. 2012; 75:181-188. 